\title{
Acolhimento Pelos 5 Sentidos: a Interação Sensorial como Estratégia para Humanização da Assistência e Qualificação do Serviço de Saúde
}

\author{
Braga, Rodrigo José Vianna Figueiredo; Lima, Marina Dayrell de Oliveira; Barata, \\ Jaqueline Lara Marques \\ Pontifícia Universidade Católica de Minas Gerais — digo-life@hotmail.com
}

Introdução: como proposta para reduzir as dificuldades encontradas durante o tratamento e favorecer a recuperação da comunicação entre a equipe de profissionais de saúde e o usuário, o Ministério da Saúde regulamentou o PNH - Programa Nacional de Humanização da Assistência Hospitalar (PESSINE; BERTACHINI, 2011). o PNH prioriza o acolhimento, que se expressa, em suas várias definições, uma ação de aproximação, uma atitude de inclusão, de forma a atender a todos que procuram os serviços de saúde, ouvindo seus pedidos e assumindo uma postura capaz de acolher, escutar e dar respostas mais adequadas aos usuários. como dispositivo técnicoassistencial, permite a reflexão e a mudança dos modos de operar a assistência, pois questiona as relações clínicas no trabalho em saúde (BRASIL, 2006). Reconhecendo a subjetividade humana e sua relevância no processo de acolhimento, afim de que o cuidado seja realizado de forma efetiva e sensibilizada, surge a real necessidade de implementar tal projeto que preconiza a sensibilização dos profissionais de um hospital público de Minas Gerais. Objetivo: Sensibilizar os profissionais de saúde de um hospital acerca dos cinco sentidos, como estratégia para humanização da assistência e qualificação do serviço de saúde levando em consideração suas necessidades, limites e o ambiente de trabalho que os cercam. Método: Trata-se de um projeto onde serão realizadas dinâmicas com todos os profissionais de um hospital. para estimular a reflexão a partir da percepção de cada profissional, suas dificuldades ou facilidades em descobrir novos objetos e/ou sensações, serão utilizados os órgãos do sentido através de vídeos, imagens, textos e poemas, músicas, sons diversos, objetos de diferentes texturas, massagens, essências e diversos tipos de alimentos com os mais variados sabores. Resultados: Implementar um processo de humanização em setores hospitalares requer a busca de relações profissionais saudáveis, de respeito pelo diferente, reconhecimento dos limites profissionais (DAMASCENO, et al., 2009). para que os trabalhadores de saúde possam exercer a profissão com honra e dignidade, respeitar o outro e sua condição humana, dentre outros, necessitam manter sua condição humana também respeitada e valorizada, sendo o projeto propulsor de tais necessidades. Conclusão: a redescoberta dos sentidos nos processos de conhecimento, comunicação e compreensão humana é essencial à sensibilização dos profissionais do hospital, bem como ao desenvolvimento e formação profissional dos acadêmicos da instituição por permitir experimentar novas formas de produção em saúde. o projeto "Acolhimento pelos cinco sentidos" permitirá o envolvimento dos profissionais do hospital, a promoção da reflexão, da qualificação do atendimento e a busca pelo acolhimento humanizado através da valorização destes no processo saúde-doença.

Braga, Rodrigo José Vianna Figueiredo; Lima, Marina Dayrell de Oliveira; Barata, Jaqueline Lara Marques. Acolhimento Pelos 5 Sentidos: a Interação Sensorial como Estratégia para Humanização da Assistência e Qualificação do Serviço de Saúde. In: Anais do Congresso Internacional de Humanidades \& Humanização em Saúde [= Blucher Medical Proceedings, num.2, vol.1]. São Paulo: Editora Blucher, 2014. ISSN 2357-7282 